Article

\title{
Benzyl and Methyl Fatty Hydroxamic Acids Based on Palm Kernel Oil as Chelating Agent for Liquid-Liquid Iron(III) Extraction
}

Md Jelas Haron ${ }^{1, *}$, Hossein Jahangirian ${ }^{1, *}$, Sidik Silong ${ }^{1}$, Nor Azah Yusof ${ }^{1}$, Anuar Kassim ${ }^{1}$, Roshanak Rafiee-Moghaddam ${ }^{2}$, Behnam Mahdavi ${ }^{2}$, Mazyar Peyda ${ }^{3}$, Yadollah Abdollahi ${ }^{4}$ and Jamileh Amin 1

1 Department of Chemistry, Faculty of Science, Universiti Putra Malaysia, 43400 UPM, Serdang, Selangor, Malaysia; E-Mails: sidik@science.upm.edu.my (S.S.); azah@science.upm.edu.my (N.A.Y.); anuar@science.upm.edu.my (A.K.); jaamin2000@yahoo.com (J.A.)

2 School of Chemical Sciences and Food Technology, Faculty of science and Technology, Universiti Kebangsaan Malaysia, 43600 UKM Bangi, Selangor, Malaysia; E-Mails: roshanak.rafiee@gmail.com (R.R.-M.); behnammahdavi@yahoo.com (B.M.)

3 Department of Chemical and Environmental Engineering, Faculty of Engineering, Universiti Putra Malaysia, 43400 UPM, Serdang, Selangor, Malaysia; E-Mail: mazyarpeyda@yahoo.com

4 Advanced Materials and Nanotechnology Laboratory, Institute of Advanced Technology, Universiti Putra Malaysia, 43400 UPM, Serdang, Selangor, Malaysia;

E-Mail: yadollahabdolla@putra.upm.edu.my

* Authors to whom correspondence should be addressed;

E-Mail: mdjelas@science.upm.edu.my (M.J.H.); kamran.jahangirian@yahoo.com (H.J.);

Tel.: +60-3-8946-6601 (M.J.H.); +60-1-7300-8372 (H.J.); Fax: +60-3-8946-6601 (M.J.H.; H.J.).

Received: 26 December 2011; in revised form: 29 January 2012 / Accepted: 8 February 2012 / Published: 16 February 2012

Abstract: Liquid-liquid iron(III) extraction was investigated using benzyl fatty hydroxamic acids (BFHAs) and methyl fatty hydroxamic acids (MFHAs) as chelating agents through the formation of iron(III) methyl fatty hydroxamate (Fe-MFHs) or iron(III) benzyl fatty hydroxamate (Fe-BFHs) in the organic phase. The results obtained under optimized conditions, showed that the chelating agents in hexane extract iron(III) at $\mathrm{pH} 1.9$ were realized effectively with a high percentage of extraction $(97.2 \%$ and $98.1 \%$ for MFHAs and BFHAs, respectively). The presence of a large amount of $\mathrm{Mg}(\mathrm{II}), \mathrm{Ni}(\mathrm{II})$, $\mathrm{Al}(\mathrm{III}), \mathrm{Mn}(\mathrm{II})$ and $\mathrm{Co}(\mathrm{II})$ ions did affect the iron(III) extraction. Finally stripping studies 
for recovering iron(III) from organic phase (Fe-MFHs or Fe-BFHs dissolved in hexane) were carried out at various concentrations of $\mathrm{HCl}, \mathrm{HNO}_{3}$ and $\mathrm{H}_{2} \mathrm{SO}_{4}$. The results showed that the desired acid for recovery of iron(III) was $5 \mathrm{M} \mathrm{HCl}$ and quantitative recovery of iron(III) was achieved from Fe(III)-MFHs and Fe(III)-BFHs solutions in hexane containing $5 \mathrm{mg} / \mathrm{L}$ of $\mathrm{Fe}(\mathrm{III})$.

Keywords: Iron extraction; methyl fatty hydroxamic acid; benzyl fatty hydroxamic acid; iron(III) methyl fatty hydroxamate; iron(III) benzyl fatty hydroxamate; palm kernel oil

\section{Introduction}

Separation and concentration of metal ions including iron(III) are important from the perspective of both environmental and economic profits. Many reagents have been used for extraction and separation of iron(III) from aqueous solutions [1]. Recently Rios et al. reported an unconventional solvent less method for iron(III) extraction using ionic liquids. They reported that the ionic liquid methyltrioctylammonium chloride allowed almost complete extraction of iron(III) from the aqueous solutions [2]. Although the results of the iron(III) extraction with ionic liquids as an alternative to the traditional liquid-liquid extraction is very promising, they suffer from some drawbacks such as toxicity and high cost of the reagent [3]. Hence many workers still use the conventional methods which use chelating reagents to chelate metal ions and extraction into organic solvents. Jayachandran et al. studied the liquid-liquid extraction of iron(III) with 2-ethyl hexyl phosphonic acid mono 2-ethyl hexyl ester (PC-88A) in toluene. They showed that quantitative extraction of iron(III) with $5 \times 10^{-3} \mathrm{M}$ PC-88A in toluene was achieved in the $\mathrm{pH}$ range $0.75-2.5$. From the extracted complex species in the organic phase, iron(III) was stripped with 1-4 $\mathrm{M} \mathrm{HNO}_{3}, 1.5-4 \mathrm{M} \mathrm{H}_{2} \mathrm{SO}_{4}$ and 1.5-4 M HCl. Finally they extended the method for the determination of iron in real samples [4]. Saji and Reddy used a mixed solvent system consisting of tributyl phosphate and methyl isobutyl ketone for extraction of iron(III) from hydrochloric acid solution. The results demonstrate that iron(III) is extracted as $\mathrm{HFeCl}_{4}$ with 2 mol of the solvent. The potential of the mixed solvent system for the recovery of high purity iron(III) chloride from waste chloride liquors of titanium minerals in the processing industry has been assessed [5].

Hydroxamic acids and their derivatives have been known as metal chelating compounds for more than a half century. The compounds were applied for organometal synthesis, spectroscopic analysis and metal extraction [6-15]. Chiarizia et al. studied the extraction kinetics of iron(III) at biphasic medium [16]. They investigated the forward and reverse extraction rate of $\mathrm{Fe}^{3+}$ at time zero between aqueous nitrate solutions and toluene solutions of tri-n-butylacetohydroxamic acid, and showed that the extraction reactions occur simultaneously in the aqueous phase (homogeneous path) and at the interface (heterogeneous path) and also correlation between the rate constants and the equilibrium constant of the extraction reaction of Fe(III) has been established. Afeworki and Chandravanshi innovated simple, precise, sensitive, and highly selective methods for the separate determination of iron(III) and cobalt(II) and for the simultaneous determination of both metal ions [17]. They showed that iron(III) and cobalt(II) react with thiocyanate in the presence of 
$\mathrm{N}$-phenylcinnamohydroxamic acid to form pinkish red and blue colored complexes, respectively and are quantitatively extractable into ethylacetate from $0.5-1.5 \mathrm{M}$ hydrochloric acid solutions. They studied the effects of foreign ions and various experimental parameters to optimize the conditions for the extraction and used the methods in the analysis of blood, vitamin $\mathrm{B}_{12}$, and standard steels for iron and cobalt successfully. Birus and Van Eldik studied the effect of pressure on the complex formation and aquation kinetics of iron(III) with many hydroxamic acids[18]. Agrawal et al. reported a new functionalized calyx[6]crown hydroxamic acid for the speciation, liquid-liquid extraction, sequential separation and trace determination of $\mathrm{Cr}(\mathrm{III}), \mathrm{Mo}(\mathrm{VI})$ and $\mathrm{W}(\mathrm{VI})$ [19]. They investigated effect of different parameters such as $\mathrm{pH} / \mathrm{M} \mathrm{HCl}$, time, temperature and concentration of calyx[6]crown hydroxamic acid on the extraction and obtained optimum condition for this purpose. They also obtained suitable extracting organic solvent and determined the stoichiometry of the complex. Chromium(III), molybdenum(VI) and tungsten(VI) were extracted at $\mathrm{pH} 4.5,1.5 \mathrm{M} \mathrm{HCl}$ and $6.0 \mathrm{M}$ $\mathrm{HCl}$, respectively with calixcrown hydroxamic acid in chloroform in the presence of a large number of cations and anions.

In this study we applied MFHAs and BFHAs based on palm kernel oil as chelating agent for extraction of $\mathrm{Fe}^{3+}$ from aqueous media by using liquid-liquid extraction. This is the first report of using fatty hydroxamic acids derivatives as iron chelating agents. The synthesis of MFHAs and BFHAs from palm kernel oil is simple, environmentally friendly and uses easily available palm kernel oil as one of the raw materials [20].

\section{Results and Discussion}

\subsection{Organic Solvent Selection and Volume Ratio Org/Aq Phases Determination}

Different kinds of organic solvent such as heptane, hexane, petrolum ether, xylene and chloroform were applied on iron(III) extraction by MFHAs as chelating agent. Since our aim was to evaluate the ability of MFHAs to extract iron(III), we choose organic solvents that do not have extraction properties for the metal ion. Table 1 shows that heptane gave the highest percentage of iron(III) extraction followed by hexane and xylene gave the lowest. The high percentage of iron(III) extraction in heptane and hexane could be due to MFHAs having linear alky branch which is more soluble in hydrocarbon compared to other types of organic solvents. However due to the cheaper cost of hexane compared to heptane, and the percentage of iron(III) extraction differing only by $0.3 \%$, hexane was selected as solvent in the subsequent experiment. In order to select the optimum volume ratio of organic aqueous phase, various volumes of hexane containing $3500 \mathrm{mg} / \mathrm{L}$ MFHAs were used to extract iron(III) from $50 \mathrm{~mL}$ aqueous solution containing $100 \mathrm{mg} / \mathrm{L}$ iron(III). It was found that (data not shown) the highest percentage of extraction was achieved when the volume ratio of org/aq is equal to 1 ( $50 \mathrm{~mL}$ org/50 $\mathrm{mL}$ aq). 
Table 1. Effect of various organic solvents on the iron(III) extraction by methyl fatty hydroxamic acids (MFHAs): $\left[\mathrm{Fe}^{3+}\right]_{(\mathrm{aq})}=100 \mathrm{mg} / \mathrm{L},[\mathrm{MFHAs}]_{(\mathrm{org})}=3500 \mathrm{mg} / \mathrm{L}, \mathrm{pH}_{(\mathrm{aq})}=3.0$, $\mathrm{V}_{\text {org }}=50 \mathrm{~mL}, \mathrm{~V}_{\mathrm{aq}}=50 \mathrm{~mL}$.

\begin{tabular}{ccc}
\hline $\begin{array}{c}\text { Organic } \\
\text { Solvent }\end{array}$ & $\begin{array}{c}\text { Final }\left[\mathrm{Fe}^{3+}\right](\mathrm{aq}) \\
(\mathrm{mg} / \mathrm{L})\end{array}$ & $\begin{array}{c}\text { Extraction } \\
(\%)\end{array}$ \\
\hline Heptane & 24.8 & 75.2 \\
Hexane & 25.0 & 75.0 \\
Petrolum ether & 38.57 & 61.5 \\
Chloroform & 35.5 & 64.5 \\
Xylene & 49.9 & 50.1 \\
\hline
\end{tabular}

\subsection{Effect of pH on Iron(III) Extraction}

Rydberg et al. [21] described the equation of liquid-liquid metal extraction by chelating agents can be written by Equation 1:

$$
\mathrm{Fe}_{(\mathrm{aq})}^{3+}+\mathrm{xHL}_{(\mathrm{org})} \stackrel{\mathrm{K}_{\mathrm{ex}}}{\rightleftarrows} \mathrm{FeL}_{\mathrm{x}(\mathrm{org})}+\mathrm{xH}_{(\mathrm{aq})}^{+}
$$

Where $\mathrm{HL}, \mathrm{FeL}_{\mathrm{x}}, \mathrm{x}$ and $\mathrm{K}_{\mathrm{ex}}$ are chelating agent, iron complex, mole ratio of chelate to $\mathrm{Fe}^{3+}$ in the complex, and the equilibrium constant of the reaction, respectively. This equation shows iron extraction depend on aqueous $\mathrm{pH}\left(\left[\mathrm{H}^{+}\right]_{\mathrm{aq}}\right)$ so effect of $\mathrm{pH}$ on the iron(III) extraction was carried out in different $\mathrm{pH}(1.0,1.5,1.8,1.9,2.0,2.1,2.2,2.5$ and 3.0) of aqueous phase while other parameters were kept constant. The result in Figure 1 shows that $\mathrm{pH} 1.9$ gives the highest percentage of extraction. The down curve at $\mathrm{pH}$ above 1.9 could be due to the decrease of solubility of $\mathrm{Fe}^{3+}$ while the down curve at $\mathrm{pH}$ lower than 1.9 could be due to proton exchange reaction as shown in schemes 1 and 2 (decreasing concentration of MFHs (methyl fatty hydroxamates) anions). This fact is supported by Equation 1 which shows that increasing $\left[\mathrm{H}^{+}\right]$(decreasing the $\mathrm{pH}$ ) caused the equilibrium reaction move to the opposite direction of complex formation.

Figure 1. Effect of $\mathrm{pH}$ on the iron(III) extraction by MFHAs: $\left[\mathrm{Fe}^{3+}\right]_{(\mathrm{aq})}=100 \mathrm{mg} / \mathrm{L}$, $[\text { MFHAs }]_{(\text {org })}=3500 \mathrm{mg} / \mathrm{L}, \mathrm{pH}_{(\mathrm{aq})}=$ variable.

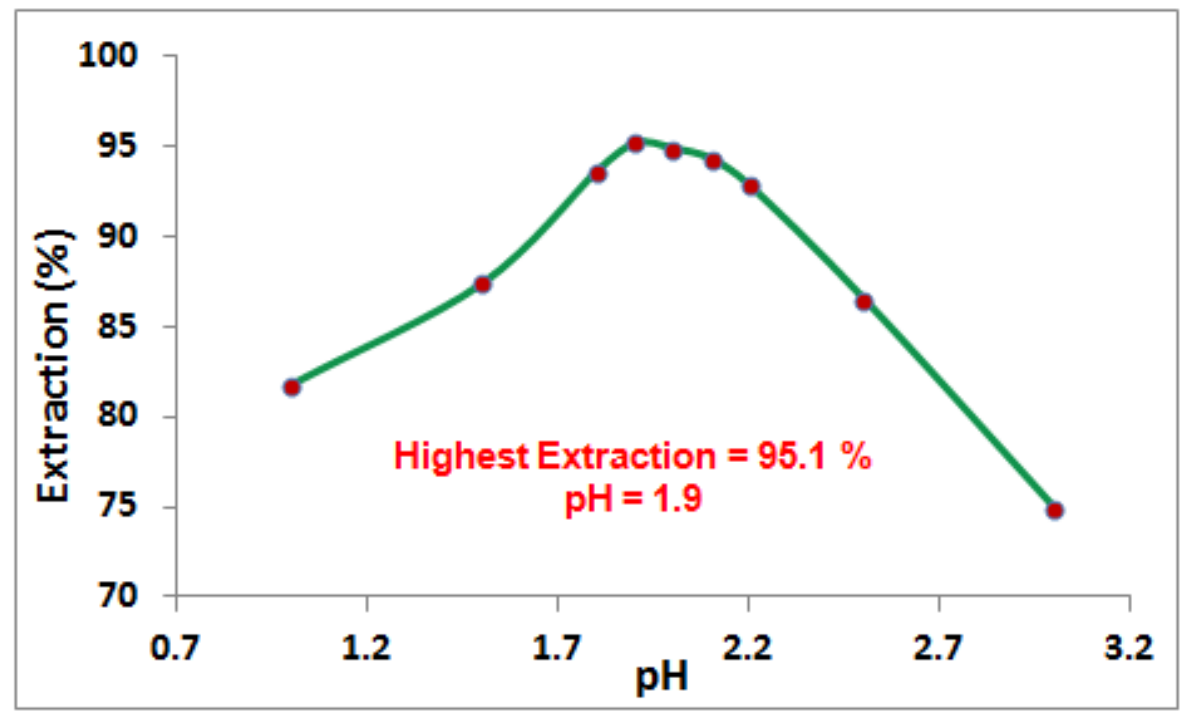




\subsection{Effect of Chelate Concentration}

For this purpose, different concentrations of MFHAs solutions in hexane were used for iron(III) extraction. The results show that the percentage of iron(III) extraction increases when MFHAs concentration in organic phase increases (Figure 2) and maximum iron(III) extraction was obtained when the concentration of MFHAs concentration was 0.0158 M. Higher concentrations of MFHAs were not investigated due to solubility limit of the chelating agent in the solvent.

Figure 2. Effect of MFHAs concentration on the iron(III) extraction: $\left[\mathrm{Fe}^{3+}\right]_{(\mathrm{aq})}=100 \mathrm{mg} / \mathrm{L}$, $\mathrm{pH}_{(\mathrm{aq})}=1.9$.

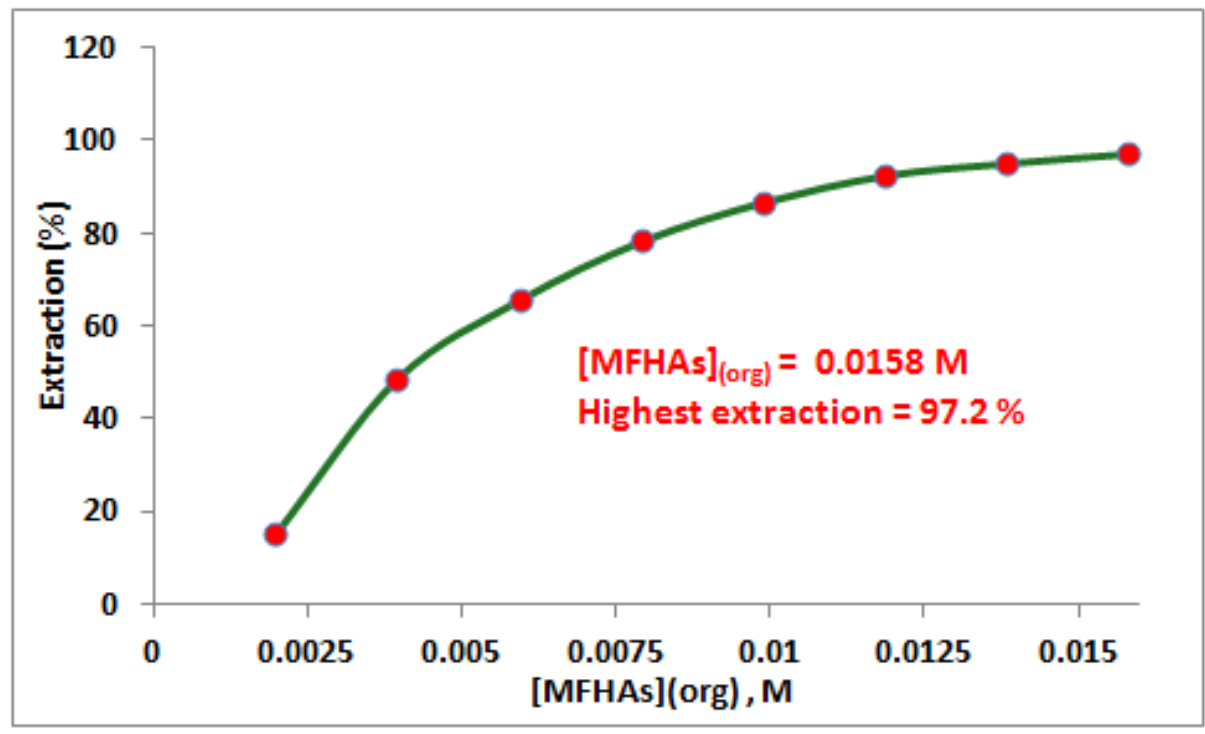

\subsection{Determination of Mole Ratio $\mathrm{MFHs} / \mathrm{Fe}^{3+}$ in Fe-MFHs}

From the equilibrium Equation 1, the equilibrium constant, $\mathrm{K}_{\mathrm{ex}}$ can be written as in Equation 2 below. By defining a distribution ratio, D, as in Equation 3 and transferring it into Equation 2, $\mathrm{K}_{\mathrm{ex}}$ can be written as in Equation 4 where its logarithm form is given in Equation 5. According to Equation 5 the mole ratio, $\mathrm{x}$, of the MFHAs to $\mathrm{Fe}^{3+}$ in the complex can be determined from the slope of the plot $\log$ D versus $\log$ [MFHAs]. The data of the effect of MFHAs concentrations on iron(III) extraction in the previous section were used to plot log D versus log [MFHAs] shown in Figure 3. The figure shows that the mole ratio of MFHAs to $\mathrm{Fe}^{3+}$ in the complex is equal to 2.5. This result indicates that mixture of complexes with mole ratios 2 and 3 of MFHAs per mole of iron(III) were formed at $\mathrm{pH}=1.9$. This result is in agreement with that of Farkas et al. [22] that described the mole ratio of monohydroxamic acids ligand per mole of iron(III) are dependent on $\mathrm{pH}$ and also indicated that the mixture of different species of complexes with different mole ratios of ligand per metal could exist in a specific $\mathrm{pH}$ value.

$$
\begin{gathered}
\mathbf{K}_{\mathbf{e x}}=\frac{\left[\mathrm{FeL}_{\mathbf{x}}\right]_{(\mathrm{org})}\left[\mathbf{H}^{+}\right]_{(\mathbf{a q})}^{\mathbf{x}}}{\left[\mathrm{Fe}^{3+}\right]_{(\mathbf{a q})}[\mathbf{H L}]_{(\mathbf{o r g})}^{\mathbf{x}}} \\
\mathbf{D}=\frac{\left[\mathbf{F e L}_{\mathbf{x}}\right]_{(\mathbf{o r g})}}{\left[\mathbf{F e}^{3+}\right]_{(\mathbf{a q})}}
\end{gathered}
$$




$$
\begin{gathered}
\mathbf{K}_{\mathrm{ex}}=\frac{\mathrm{D}\left[\mathrm{H}^{+}\right]_{(\mathbf{a q})}^{\mathrm{x}}}{[\mathrm{HL}]_{(\mathrm{org})}^{\mathrm{x}}} \\
\log \mathbf{D}=\mathbf{x} \log [\mathbf{H L}]_{(\mathrm{org})}+\log \mathbf{K}_{\mathrm{ex}+}+\mathbf{x} \mathbf{p H}
\end{gathered}
$$

Figure 3. Curve of $\log \mathrm{D}$ versus logarithm of MFHAs concentration in hexane: $\left.\left[\mathrm{Fe}^{3+}\right]_{(\mathrm{aq})}=100 \mathrm{mg} / \mathrm{L}, \mathrm{pH}_{(\mathrm{aq}}\right)=1.9$.

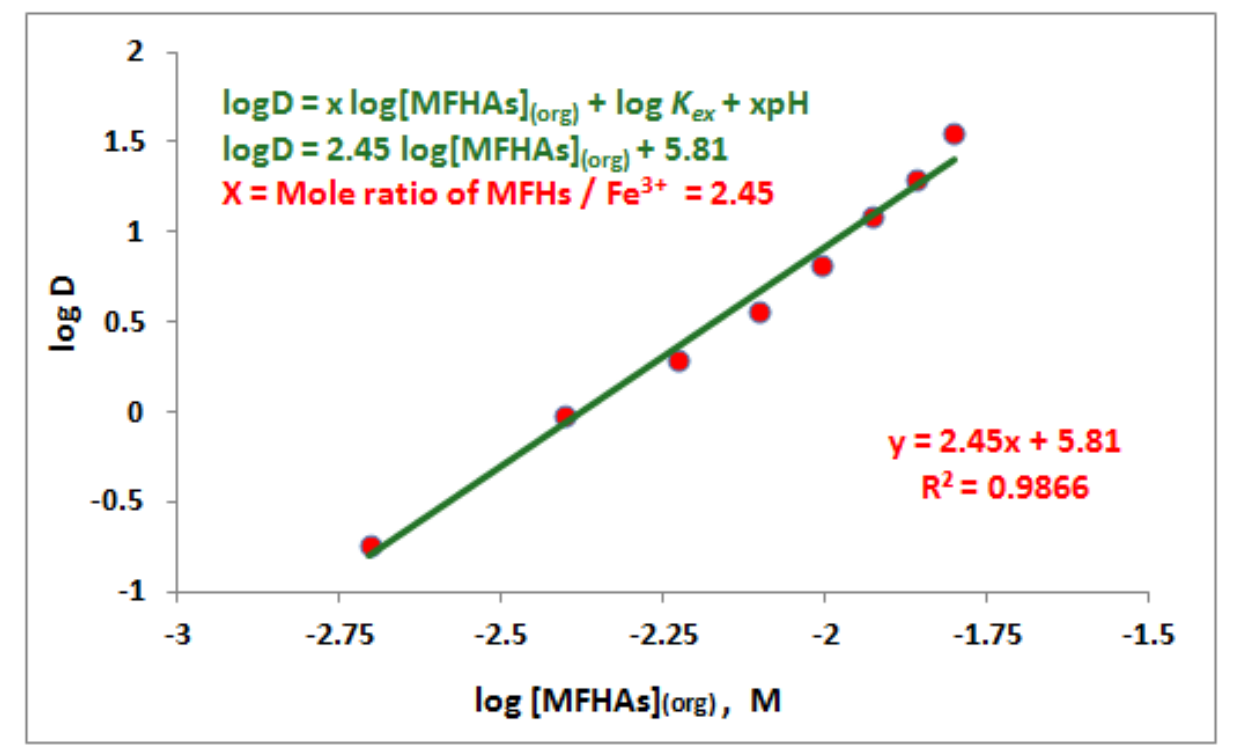

\subsection{Comparison of Iron Extraction by MFHAs and BFHAs}

Previous results show that the optimum conditions for extraction of iron(III) from aqueous solution containing $100 \mathrm{mg} / \mathrm{L} \mathrm{Fe}^{3+}$ by MFHAs are as follows: [MFHAs] (org) $=0.0158 \mathrm{M}, \mathrm{pH}$ of aqueous solution $=1.9$ and $\mathrm{V}_{\text {org }} / \mathrm{V}_{\mathrm{aq}}=50 \mathrm{~mL} / 50 \mathrm{~mL}$. These conditions were applied for comparing iron(III) extraction by MFHAs and BFHAs. The results showed that the percentage extraction for MFHAs and BFHAs were found to be $97.2 \%$ and $98.1 \%$. A small difference on iron(III) extraction ability between MFHAs and BFHAs ligands could be due to a slight difference in ligands solubility or dissociation to anions due to small differences in electron affinity or steric effect of methyl and benzyl groups.

\subsection{Iron(III) Separation by MFHAs and BFHAs}

In the liquid-liquid extraction, the ability of an extractant to separate a metal ion from another metal ion is measured by a separation factor, SF which is given by Equation 6 :

$$
\mathrm{SF}_{(\mathrm{M} / \mathrm{N})}=\mathbf{D}_{\mathrm{M}} / \mathbf{D}_{\mathrm{N}}
$$

Where $D_{M}$ is the distribution ratio of metal $M$ and $D_{N}$ is the distribution ration of metal $N$ [23]. The results of iron(III) extraction from aqueous solution containing $100 \mathrm{mg} / \mathrm{L} \mathrm{Fe}^{3+}$ in the presence of similar concentrations of either $\mathrm{Mg}$ (II), Ni (II), Al (III), Mn (II) or Co (II) show that the values of SF were higher than 10,000 for both MFHAs and BFHAs ligands. This indicates that the fatty acid derivatives could be effectively used to separate iron(III) from those metal ions. Iron(III) extraction by MFHAs and BFHAs from aqueous solution containing $100 \mathrm{mg} / \mathrm{L}$ of $\mathrm{Fe}(\mathrm{III})$ in the absence and in the presence of $800 \mathrm{mg} / \mathrm{L}$ of metal ions such as $\mathrm{Mg}(\mathrm{II}), \mathrm{Ni}(\mathrm{II}), \mathrm{Al}(\mathrm{III}), \mathrm{Mn}(\mathrm{II})$ and $\mathrm{Co}(\mathrm{II})$ were carried out. 
The results in Table 2 show that the presence of the above mentioned ions at high concentration did not significantly affect the percentages of iron(III) extraction.

Table 2. Effect of foreign ions on the iron(III) extraction by MFHAs and BFHAs ligands: $\left[\mathrm{Fe}^{3+}\right]_{(\mathrm{aq})}=100 \mathrm{mg} / \mathrm{L},[\text { foreign metal ions }]_{(\mathrm{aq})}=800 \mathrm{mg} / \mathrm{L},[\mathrm{MFHAs}]_{(\mathrm{org})}=[\mathrm{BFHAs}]_{(\mathrm{org})}=$ $0.0158 \mathrm{M}, \mathrm{pH}_{(\mathrm{aq})}=1.9$. Ex. $=$ Extraction, $\mathrm{SD}=$ standard deviation.

\begin{tabular}{ccc}
\hline Metal Ions & $\begin{array}{c}\text { MFHAs } \\
\text { Ex. }(\%) \pm \text { SD }\end{array}$ & $\begin{array}{c}\text { BFHAs } \\
\text { Ex. }(\%) \pm \text { SD }\end{array}$ \\
\hline None & $95.1 \pm 0.4$ & $96.2 \pm 0.6$ \\
Mg(II) & $94.8 \pm 0.4$ & $95.9 \pm 0.6$ \\
Ni(II) & $94.9 \pm 0.5$ & $95.9 \pm 0.8$ \\
Al(III) & $94.9 \pm 0.5$ & $96.1 \pm 0.4$ \\
Mn(II) & $94.6 \pm 0.6$ & $95.8 \pm 0.7$ \\
Co(II) & $\mathbf{9 4 . 6} \pm 0.5$ & $95.7 \pm 0.5$ \\
\hline
\end{tabular}

\subsection{Iron(III) Stripping and Preconcentration}

Equation 1 in Section 2.2 shows that in solvent extraction the formation of iron(III) complexes in the organic phase is dependent on the aqueous $\mathrm{pH}$ or $\mathrm{H}^{+}$concentration, indicating that the stability of the complexes in the organic phase can be reduced by decreasing the aqueous $\mathrm{pH}$. Accordingly, for iron(III) stripping from Fe-MFHs and Fe-BFHs in the organic phase to the aqueous phase can be achieved by using a strong mineral acid solution. Iron(III) stripping was then carried out by mixing $50 \mathrm{~mL}$ organic phase (hexane) containing iron(III) fatty hydroxamate derivatives with the same volume of different acids at various concentrations separately $\left(\mathrm{V}_{\mathrm{or}} / \mathrm{V}_{\mathrm{aq}}=1\right)$. The initial iron(III) concentration in organic phase is equal to $95 \mathrm{mg} / \mathrm{L}$. The mixture was stirred at $500 \mathrm{rpm}$ for 10 minutes at $25 \pm 1{ }^{\circ} \mathrm{C}$. The results in Table 3 show that the highest recovery of iron(III) was obtained by $5 \mathrm{M}$ hydrochloric acid. This result can be due to easier formation of $\mathrm{FeCl}_{3}$ compared to $\mathrm{Fe}\left(\mathrm{NO}_{3}\right)_{3}$ and $\mathrm{Fe}_{2}\left(\mathrm{SO}_{4}\right)_{3}$ which can be due to differences in the steric effect of anions, $\mathrm{Cl}^{-}, \mathrm{NO}_{3}{ }^{-}$and $\mathrm{SO}_{4}{ }^{2-}$ for formation of the mentioned salts in aqueous phase. Also, the recovery percentage from Fe-MFHs (99.0\%) is higher than that of Fe-BFHs (97.9\%). This may be due to a lower stability of Fe-MFHs compared to $\mathrm{Fe}-\mathrm{BFH}$ in $\mathrm{HCl}$ medium. In the next experiment, the effect of volume ratio of organic phase per aqueous phase $(5 \mathrm{M} \mathrm{HCl})$ in the stripping process was investigated. Different volume ratio of org/aq such as $4 / 1,3 / 1,2 / 1,1 / 1$ and $1 / 2$ were applied for iron(III) stripping. The results in Table 4 show that highest recovery percentages were obtained while volume ratio of org/aq was $1 / 2$. This result is expected because with increasing the volume of aqueous phase, the amount of proton increases too and consequently stripping will be more effectively completed. Finally, the effect of initial concentrations of iron(III) in the organic phase, on the stripping was investigated using the different concentrations of Fe(III) (in organic phase) such as 95, 50, 25, 10, $5 \mathrm{mg} / \mathrm{L}$ while other conditions were kept constant. The results in Table 5 show that the quantitative recovery was achieved as $[\mathrm{Fe}(\mathrm{III})]_{(\text {org })}$ was $5 \mathrm{mg} / \mathrm{L}$ for both Fe-MFHs and Fe-BFHs. 
Table 3. Effect of type and concentration of mineral acids on the iron(III) stripping from Fe-MFHs and Fe-BFHs: initial $\left[\mathrm{Fe}^{3+}\right]_{(\text {org })}=95 \mathrm{mg} / \mathrm{L}, \mathrm{V}_{\text {org }} / \mathrm{V}_{\mathrm{aq}}=50 \mathrm{~mL} / 50 \mathrm{~mL}$. Rec. $=$ recovery.

\begin{tabular}{cccc}
\hline Acids & $\begin{array}{c}\text { Conc. } \\
(\mathrm{M})\end{array}$ & $\begin{array}{c}\text { Fe (\% Rec.) } \\
\text { Fe-MFHs }\end{array}$ & $\begin{array}{c}\text { Fe (\% Rec.) } \\
\text { Fe-BFHs }\end{array}$ \\
\hline \multirow{3}{*}{$\mathrm{HCl}$} & $1(\mathrm{M})$ & 60.5 & - \\
& $3(\mathrm{M})$ & 94.1 & - \\
& $5(\mathrm{M})$ & 99.0 & 97.9 \\
\hline \multirow{2}{*}{$\mathrm{HNO}_{3}$} & $1(\mathrm{M})$ & 27.5 & - \\
& $3(\mathrm{M})$ & 55.7 & - \\
& $5(\mathrm{M})$ & 70.3 & 73.7 \\
\hline & $1(\mathrm{M})$ & 29.0 & - \\
$\mathrm{H}_{2} \mathrm{SO}_{4}$ & $3(\mathrm{M})$ & 56.9 & - \\
& $5(\mathrm{M})$ & 79.7 & 86.1 \\
\hline
\end{tabular}

Table 4. Effect of volume ratio of organic phase per aqueous phase on the iron(III) stripping of Fe-MFHAs and Fe-BFHAs: initial $\left[\mathrm{Fe}^{3+}{ }_{(\text {org })}\right]=95 \mathrm{mg} / \mathrm{L}$, aqueous phase $=\mathrm{HCl}$ $(5 \mathrm{M})$, Rec. $=$ recovery.

\begin{tabular}{ccc|}
\hline $\begin{array}{c}\text { Volume Ratio } \\
\text { (org/aq) }\end{array}$ & $\begin{array}{c}\text { Fe (\% Rec.) } \\
\text { Fe-MFHs }\end{array}$ & $\begin{array}{c}\text { Fe (\% Rec.) } \\
\text { Fe-BFHs }\end{array}$ \\
\hline $4 / 1$ & 71.3 & 70.1 \\
$3 / 1$ & 89.7 & 86.6 \\
$2 / 1$ & 97.2 & 93.5 \\
$1 / 1$ & 99.1 & 97.9 \\
$1 / 2$ & 99.1 & 98.3 \\
\hline
\end{tabular}

Table 5. Effect of initial iron(III) concentration in the organic phase on the iron(III) stripping of Fe-MFHAs and Fe-BFHAs: $\mathrm{V}_{\text {org }} / \mathrm{V}_{\mathrm{aq}}=25 \mathrm{cc} / 50 \mathrm{cc}=1 / 2$, aqueous phase $=\mathrm{HCl}$ $(5 \mathrm{M})$, Rec. $=$ recovery, $\mathrm{SD}=$ standard deviation.

\begin{tabular}{ccc}
\hline $\begin{array}{c}\text { Initial }\left[\mathrm{Fe}^{3+}\right]_{(\text {org })} \\
\mathrm{mg} / \mathrm{L}\end{array}$ & $\begin{array}{c}\text { Fe }(\% \text { Rec. } \pm \text { SD }) \\
\text { Fe-MFHs }\end{array}$ & $\begin{array}{c}\text { Fe (\% Rec. } \pm \text { SD }) \\
\text { Fe-BFHs }\end{array}$ \\
\hline 95 & $99.1 \pm 0.4$ & $98.3 \pm 0.6$ \\
50 & $99.8 \pm 0.3$ & $98.8 \pm 0.5$ \\
25 & $99.9 \pm 0.6$ & $99.1 \pm 0.3$ \\
10 & $99.9 \pm 0.5$ & $99.6 \pm 0.4$ \\
5 & $100 \pm 0.2$ & $100 \pm 0.2$ \\
\hline
\end{tabular}

\section{Experimental}

\subsection{Material and Apparatus}

Sodium acetate, iron(III) chloride, $N$-methylhydroxylamine hydrochloride, and $N$-benzylhydroxylamine hydrochloride were purchased from Aldrich (USA). Hexane, heptane, chloroform, 
petroleum ether, xylene, hydrochloric acid, sulphuric acid, nitric acid and sodium hydroxide were supplied by Systerm Co. (Malaysia). Lipozyme TL IM was purchased from Novo Nordisk (Denmark). Commercial palm kernel oil was supplied by Malaysian Palm Oil Board (MPOB, Malaysia). The standard solutions of metal ions for AAS measurements were prepared by diluting the Spectrosol stock solution from BDH Chemical (England). Atomic absorption spectrophotometer (AA-680 Shimadzu, Japan) with an air-acetylene flame was used for the metal ion analyses.

\subsection{Synthesize of Chelating Agent}

MFHAs and BFHAs were separately synthesized from palm kernel oil and $N$-methylhydroxylamine hydrochloride, or $N$-benzyl-hydroxylamine hydrochloride catalyzed by Lipozyme TL IM according to the method reported recently by our group [20,24]. The molecular weight of MFHAs and BFHAs were 264 and $358 \mathrm{~g} / \mathrm{mol}$, respectively as determined from elemental analysis data as reported earlier [20].

\subsection{General Iron(III) Extraction Procedure}

A known amount of each fatty hydroxamic acids derivatives dissolved in $50 \mathrm{~mL}$ of an organic solvent was mixed with $50 \mathrm{~mL}$ aqueous solution of known concentration of iron(III) nitrate solution buffered by sodium acetate at desired $\mathrm{pH}(\mathrm{pH}=1.8$ to 2.1$)$. The mixtures were stirred at $500 \mathrm{rpm}$ at $25 \pm 1{ }^{\circ} \mathrm{C}$ for 10 minutes. Finally the organic phase was separated from aqueous phase and the amounts of iron(III) in the two phases were determined by atomic absorption spectrophotometer (AAS).

For optimization of iron(III) extraction, firstly the MFHAs was selected as a chelating agent and the effects of kind of organic phase, ligand concentration in organic phase, aqueous phase $\mathrm{pH}$ and volume ratio of organic/aqueous phases were evaluated. The optimized conditions for iron(III) extraction by MFHAs were applied to iron(III) extraction by BFHAs. The extraction percentages were calculated from the following formula (Equation 7):

$$
\text { Extraction (\%) }=\mathrm{A} \times 100 / \mathrm{B}
$$

Where $\mathrm{A}=$ final amount of iron(III) in the organic phase and $\mathrm{B}=$ initial amount of iron(III) in the aqueous phase. Scheme 1 shows the equation of chemical reaction of iron complexation of fatty hydroxamic acids derivatives.

Scheme 1. The equation for reaction of iron(III) complexation with fatty hydroxamic acids derivatives: $\mathrm{R}=$ methyl, or benzyl. $\mathrm{R}_{1}, \mathrm{R}_{2}, \mathrm{R}_{3}=$ alkyl branches of different acyl groups obtained from palm kernel oil [20].

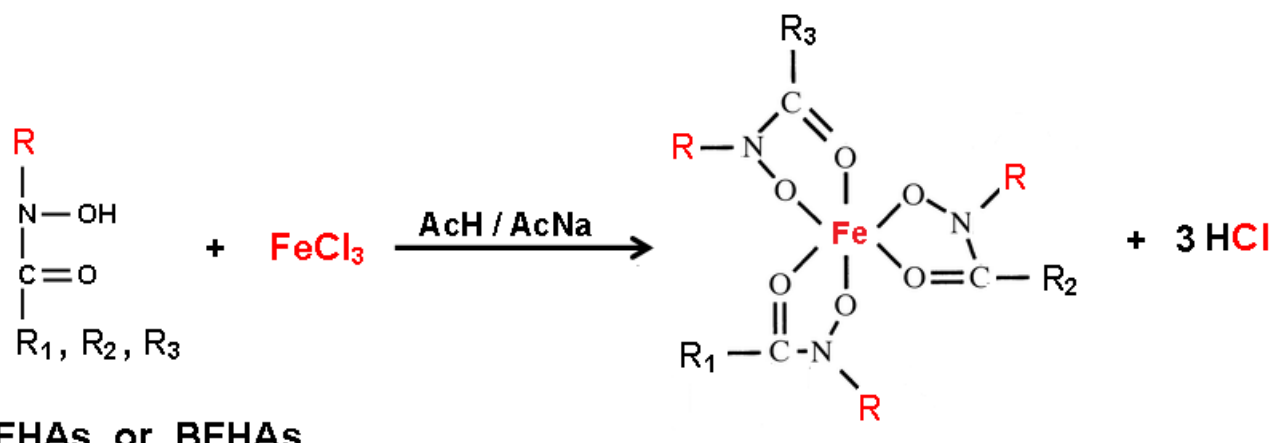




\subsection{Iron(III) Stripping Study}

The chemical reaction of iron(III) stripping is the opposite of iron(III) extraction reaction where an analyte usually is extracted back into a mineral acid. For optimizing the iron(III) stripping, various parameters such as effect of kind and concentration of mineral acid, effect of volume ratio of organic phase per aqueous phase and effect of initial iron(III) concentration in organic phase were investigated. The recovery percentage of iron(III) stripping was calculated by the Equation 8:

$$
\text { Recovery }(\%)=A \times 100 / B
$$

Where $\mathrm{A}=$ Final amount of iron(III) in aqueous phase, and B = Initial amount of iron(III) in organic phase. Scheme 2 shows the proposed equation of chemical reaction of iron(III) stripping from iron(III) fatty hydroxamate derivatives into acid solution.

Scheme 2. The reaction equations of iron(III) stripping from iron(III) fatty hydroxamate derivatives: $\mathrm{R}=$ methyl or benzyl. $\mathrm{R}_{1}, \mathrm{R}_{2}, \mathrm{R}_{3}=$ alkyl branches of different acyl groups obtained from palm kernel oil.<smiles></smiles>

Fe-MFHs or Fe-BFHs<smiles>[R16][R2]C(=O)N([R])O</smiles>

MFHAs or BFHAs

\section{Conclusions}

The MFHAs and PFHAs based on palm kernel oil are excellent chelating agents for extraction of iron(III) from aqueous mixtures. Among the advantages of using this product as ligand are its simple preparation and the use of vegetable oil (palm kernel oil) as raw material is cheap and readily available. The highest percentage of iron(III) extraction by MFHAs and BFHAs were $97.2 \%$ and 98.1\%, respectively. Separation factor (RF) for Fe(III) extraction from $\mathrm{Co}(\mathrm{II}), \mathrm{Ni}(\mathrm{II}), \mathrm{Mn}(\mathrm{II}), \mathrm{Mg}(\mathrm{II})$, and Al(III) for both MFHAs and BFHAs were higher than 10,000 which indicates that the iron(III) can be effectively separated from those ions. The presence of the above mentioned metal ions at a high concentration did not significantly affect the percentages of iron(III) extraction. The optimum conditions for extraction of $100 \mathrm{mg} / \mathrm{L}$ iron(III) with $0.0158 \mathrm{M}$ fatty hydroxamic derivatives were $\mathrm{V}_{\text {org }} / \mathrm{V}_{\mathrm{aq}}=50 \mathrm{~mL} / 50 \mathrm{~mL}$ and at $\mathrm{pH}_{(\mathrm{aq})}$ 1.9. Iron(III) ion from Fe-MFHs or Fe-BFHs in $25 \mathrm{~mL}$ hexane containing $5 \mathrm{mg} / \mathrm{L} \mathrm{Fe}(\mathrm{III})$ can be quantitatively stripped into $50 \mathrm{~mL} \mathrm{HCl}(5 \mathrm{M})$ aqueous solution. 


\section{References}

1. Agrawal, A.; Kumari, S.; Sahu, K.K. Iron and copper recovery/removal from industrial wastes: A Review. Ind. Eng. Chem. Res. 2009, 48, 6145-6161.

2. de los Rios, P.; Hernandez-Fernandez, F.J.; Lozano, L.J.; Sanchez, S; Moreno, J.I.; Godinez, C. Removal of metal ions from aqueous solutions by extraction with ionic liquids. J. Chem. Eng. Data 2010, 55, 605-608.

3. Abbott, A.P.; Frisch, G.; Hartley, J.; Ryder, K.S. Processing of metals and metal oxides using ionic liquids. Green Chem. 2011, 13, 471-481.

4. Jayachandran, J.; Dhadke, P.M. Liquid-liquid extraction separation of iron(III) with 2-ethyl hexyl phosphonic acid mono 2-ethyl hexyl ester. Talanta 1997, 44, 1285-1290.

5. Saji, J.; Reddy, M.L.P. Liquid-liquid extraction separation of iron(III) from titania wastes using TBP-MIBK mixed solvent system. Hydrometallurgy 2001, 61, 81-87.

6. Lapatnick, L.N.; Hazel, J.F.; McNabb, W.M. Thermal analysis of some metal benzohydroxamates. Anal. Chim. Acta 1966, 36, 366-371.

7. Bhura, D.C.; Tandon, S.G. Solution stability constants of bivalent metal chelates of N-phenylcrotonohydroxamic acid. J. Inorg. Nucl. Chem. 1970, 32, 2993-2997.

8. Bhura, D.C.; Tandon, S.G. Unsaturated $N$-arylhydroxamic acids as colorimetric reagents for vanadium(v): Spectrophotometric determination with $n$-phenyl-3-styrylacrylo-hydroxamic acid. Anal. Chim. Acta 1971, 53, 379-386.

9. Hojjatie, M.; Cecconie, T.; Freiser, H. The effect of substituents on the extraction behavior of hydroxamic acids. Anal. Chim. Acta 1987, 199, 49-57.

10. Thomaskutty, P.; Agrawal, Y. Separation and microdetermination of rare earth metals with $N$-phenylbenzohydroxamic acid and xylenol orange. J. Radioanal. Nucl. Chem. 1987, 116, 365-374.

11. Haraguchi, K.; Nishida, M.; Ayame, A.; Murozumi, M.; Saitoh, T.; Watanabe, H. Solvent extraction of some metal ions with alkylcarbonyl-substituted $\mathrm{N}$-phenylhydroxylamines. Anal. Sci. 1989, 5, 735-738.

12. Agrawal, Y.K.; Rao, K.V. Polyhydroxamic acids: Synthesis, ion exchange separation and atomic absorption spectrophotometric determination of divalent metal ions. React. Polym. 1995, 25, 79-87.

13. Agrawal, Y.K.; Rao, K.V. Synthesis, complexation and ion-exchange reactivity of polymethacrylohydroxamic acid. React. Funct. Polym. 1996, 31, 225-235.

14. Bisset, W.; Jacobs, H.; Koshti, N.; Stark, P.; Gopalan, A. Synthesis and metal ion complexation properties of a novel polyethyleneimine $N$-methylhydroxamic acid water soluble polymer. React. Funct. Polym. 2003, 55, 109-119.

15. Griffith, D.; Devocelle, M.; Marmion, C.J. Hydroxamic Acids: Chemistry, Bioactivity, and Solutionand Solid-Phase Synthesis. In Amino Acids, Peptides and Proteins in Organic Chemistry; Wiley-VCH Verlag GmbH \& Co. KGaA: Weinheim, Germany, 2009; pp. 93-144.

16. Chiarizia, R.; Danesi, P.R.; Fornarini, S. Extraction kinetics of iron(III) from aqueous nitrate solutions to toluene solutions of tri-n-butylacetohydroxamic acid. J. Inorg. Nucl. Chem. 1979, 41, $1465-1474$. 
17. Afeworki, S.; Chandravanshi, B.S. Simultaneous determination of iron(III) and cobalt(II) with $N$-phenylcinnamohydroxamic acid and thiocyanate by extraction and spectrophotometry. Microchim. Acta 1987, 92, 143-152.

18. Birus, M.; van Eldik, R. Effect of pressure on the complex formation and aquation kinetics of iron(III) with hydroxamic acids. Inorg. Chem. 1991, 30, 4559-4563.

19. Agrawal, Y.K.; Sharma, K.R. Speciation, liquid-liquid extraction, sequential separation, preconcentration, transport and ICP-AES determination of $\mathrm{Cr}(\mathrm{III}), \mathrm{Mo}(\mathrm{VI})$ and $\mathrm{W}(\mathrm{VI})$ with calix-crown hydroxamic acid in high purity grade materials and environmental samples. Talanta 2005, 67, 112-120.

20. Jahangirian, H.; Haron, M.J.; Yusof, N.A.; Silong, S.; Kassim, A.; Rafiee-Moghaddam, R.; Peyda, M.; Gharayebi, Y. Enzymatic synthesis of fatty hydroxamic acid derivatives based on palm kernel oil. Molecules 2011, 16, 6634-6644.

21. Rydberg, J.; Cox, M.; Musikas, C.; Choppin, G.R. Solvent Extraction Principles and Practice, 2nd ed.; Marcel Dekker Inc.: New York, NY, USA, 1992; pp.109-206.

22. Farkas, E.; Kozma, E.; Petho, M.; Herlihy, K.M.; Micera, G. Equilibrium studies on Copper(II) and Iron(III) monohydroxamates. Polyhedron 1998, 17, 3331-3342.

23. Mester, Z.; Sturgeon, R. Sample Preparation for Trace Element Analysis; Elsevier B.V.: Amsterdam, The Netherlands, 2003; Volume XLI, p.467.

24. Jahangirian, H.; Haron, M.J.; Silong, S.; Yusof, N.A. Enzymatic synthesis of phenyl fatty hydroxamic acids from canola and palm oils. J. Oleo Sci. 2011, 60, 281-286.

(C) 2012 by the authors; licensee MDPI, Basel, Switzerland. This article is an open access article distributed under the terms and conditions of the Creative Commons Attribution license (http://creativecommons.org/licenses/by/3.0/). 